\title{
High intensive internal training induce cardioprotection against ischemic reperfusion injury
}

\section{Short communication}

Cardiovascular diseases resulting in ischemic heart disease remain a major cause of morbidity and mortality all over the world and amongst the highest Non Communicable Disease (NCD) in Iran. The main attempts amongst researchers are to find out any appropriable ways to be practically able to prevent or treat the ischemic reperfusion injuries (IRI). Preconditioning (PC) is one of the main approaches to decrease the latter injuries. ${ }^{1-3}$ Ischemic preconditioning is proved to be successive in reducing the myocardial infarction., ${ }^{4,5}$ But as it has been mentioned, this and other techniques are not suitable in human life style. There should be applicable and non-invasive methods to achieved preconditioning treatment.

One of the most potent stimuli for eliciting such preconditioning is exercise. ${ }^{6,7}$ In 2013, Other researchers showed that all different kind of exercises could ended to reduction of cardiac cells death by $4 \%$ to $75 \%$ and concluded that exercise training reduced infracted size by average $34 \%$ in animal models. ${ }^{2}$ In another study, continuous endurance training (CET) protects the heart against IR. ${ }^{8}$

Certainly, in Human epidemiological studies, it was shown that myocardial-IR induced cell death reduced following regular and continuous exercise (both short-term and long-term CET) confers cardioprotection against all level of IR-induced injuries. ${ }^{9}$ Lennon et al. ${ }^{10}$ concluded that both moderate and high-intensity continuous endurance training brings about same myocardial protection against IR injury. Therefore, it seems that both duration and intensity of exercise are significant factors in accomplishing exercise-induced cardioprotection also (EICP) ${ }^{8}$ However, many investigators report that cardiovascular, muscle, and metabolic adaptations in healthy and patient populations are intensity-dependent and the beneficial effects of high intensity interval training (HIIT) rather than CET are better and more reliable for cardioprotection. ${ }^{11-16}$ HIIT is characterized by repeated bouts of high-intensity exercise interspersed by periods of rest or low-intensity exercise for recovery. ${ }^{17}$ According to the results of the previous studies, high-intensity exercise protects the heart against IR-induced diastolic dysfunction ${ }^{18}$ and is recommended for patients with coronary heart disease. ${ }^{19}$ Moreover, the existing evidence recommended that exercise intensity rather than duration and frequency is the most critical factor determining EICP. ${ }^{16,20-22}$ Some of the studies have shown the advantages of the higher-intensity exercise over the moderate-intensity, in cardioprotection..$^{22}$ Whereas considerable evidence point out that CET leads to EICP, it is uncertain whether other forms of exercise bring about EICP against IR injury. The question remains to be answered is, what can the best type of exercise in order to achieve the optimal cardioprotection against IR injury? Doubtlessly, EICP vanishes after the termination of exercise training. ${ }^{23}$ However, how long would ittake for the EICP against IR to disappearance the exercise is terminated? In this context, Lennon et al. ${ }^{23}$ reported that after 3 days of CET $(60 \mathrm{~min}, 30 \mathrm{~m} / \mathrm{min}, \sim 70$ $\% \mathrm{VO} 2 \mathrm{max}$ ), protection against myocardial stunning remains up to 9 days and is lost 18 days after exercise termination. Calvert et al. ${ }^{4}$

\author{
Volume 5 Issue 6 - 2018
}

\author{
Ali Khoshbaten \\ Department of Physiology, Baqiyatallah University of Medical \\ Sciences, Iran
}

Correspondence: Ali Khoshbaten, Cardiovascular Physiologist, Department of Physiology, Baqiyatallah University of Medical Sciences, Tehran, Iran, Tel 0098 2l 262।3134, 0098 9122975493, Email khoshbiten@yahoo.com,Prof.khoshbiten@gmail.com

Received: October 0I, 2017| Published: November 27, 2018

reported that after 4 weeks of voluntary exercise $(\sim 7.4 \pm 0.2 \mathrm{~km} / \mathrm{d})$, EICP against IR was only retained for a week after detraining. Therefore, we expected that HIIT induced cardioprotection to be more preserved to CET ( 9 days) and voluntary.

The purpose of the present writing was also to present that in our lab we have tried to examine whether short-term HIIT could reduce the incidence of ischemic-induced arrhythmias and infarct size; and if so, how long this protective effect is retained after exercise cessation. ${ }^{7,24}$ Rats were randomly assigned into sedentary, sham, and exercise groups. Rats in the exercise groups performed 5 consecutive days of HIIT on treadmill: $5 \mathrm{~min}$ warm up with $50 \% \mathrm{VO} 2 \mathrm{max}, 6 \times 2 \mathrm{~min}$ with $95-105 \%$ VO2max (about 40 to $45 \mathrm{~m} / \mathrm{min}$ ), $5 \times 2 \mathrm{~min}$ recovery with $65-75 \% \mathrm{VO} 2 \mathrm{max}$ (about 28 to $32 \mathrm{~m} / \mathrm{min}$ ), and $3 \mathrm{~min}$ cool down with $50 \%$ VO2max, all at $0 \%$ grade. Animals exposed to an in vivo cardiac IR surgery, performed at days 1, 7, and 14 following the final exercise session. Ischemia-induced arrhythmias, myocardial infarct size (IS), plasma lactate dehydrogenase (LDH) and creatinekinase (CK) activities were measured in all animals and in some experiment nitric oxide metabolites were also measured. Compared to sedentary rats, exercised animals sustained less IR injury as evidenced by a lower size of infarction (Figure 1) and lower levels of LDH and $\mathrm{CK}$ at day one and day 7 post exercise. In comparison of sedentary group, IS significantly decreased in EX-IR1 and EX-IR7 groups (50and $35 \%$, respectively), but not in EX-IR14 group (19\%). ${ }^{25,26}$ In Those experiments that nitric oxide was measured it seems that incremental changes in NO-NO3-, NO2- axis could be one of mechanisms through which HIIT program can protect the heart from $\mathrm{I} / \mathrm{R}$ injury and decrease myocardial infarction. Exercise-induced cardioprotection disappeared14 days following exercise cessation. There were no significant changes in ischemia-induced arrhythmia between exercised and sedentary rats.

The results clearly demonstrate that HIIT protects the heart against myocardial IR injury. This protective effect can be sustained for at least one week following the cessation of the training. 


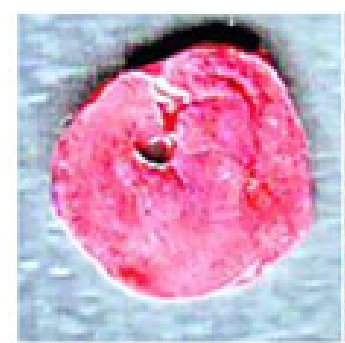

Control

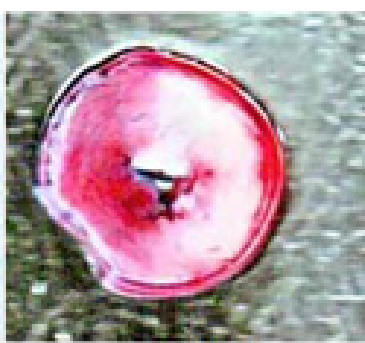

$\mathrm{CO}-\mathrm{IR}$

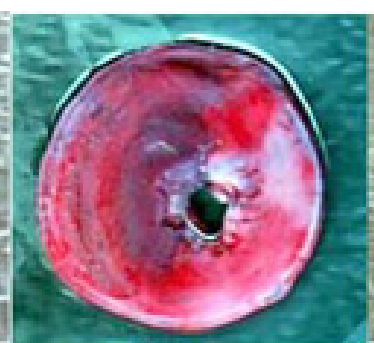

EX1

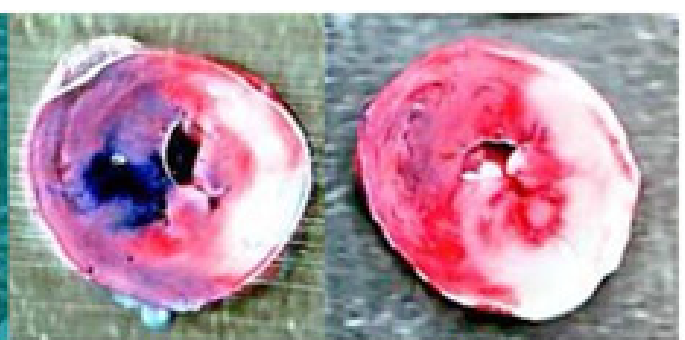

EX7
EX14

Figure 1 The ratio of myocardial area at risk to left ventricle area (AAR/LV\%) and infarct size to area at risk (IS/AAR\%) in rats subjected to 30min ischemia and $90 \mathrm{~min}$ of reperfusion. Red areas indicate myocardium within the area at risk for infarction and whitish areas indicate infracted tissue. CO-IR, control + ischemiareperfusion; EX-IR1, exercise + IR performed after a day of rest; EX-IR7, exercise + IR performed after 7 days of rest; EX-IR14, exercise + IR performed after 14 days of rest.

\section{Acknowledgments}

None.

\section{Conflicts of interest}

The author declares there is no conflicts of interest.

\section{References}

1. Foadoddini M, Esmaeilidehaj M, Mehrani H, et al. Pretreatment with hyperoxia reduces in vivo infarct size and cell death by apoptosis with an early and delayed phase of protection. Eur J Cardiothorac Surg. 2011;39(2):233-240.

2. Calvert JW, Lefer DJ. Role of $\beta$-adrenergic receptors and nitric oxide signalling in exercise-mediated cardioprotection. Physiology. 2013;28(4):216-224.

3. Safari F, Hajizadeh S, Shekarfroush S, et al. Influence of ramiprilat and losartan on ischemia reperfusion injury in rat hearts. $J$ Renin Angiotensin Aldosterone Syst. 2011;13(1):29-35.

4. Calvert JW. Cardioprotective effects of nitrite during exercise. Cardiovasc Res. 2011;89(3):499-506.

5. Shekarforoush S, Foadoddini M, Khoshbaten A. Cardiac effects of cupping: myocardial infarction, arrhythmias, heart rate and mean arterial blood pressure in the rat heart. Chin J Physiol. 2012;55(4):253-258.

6. Quindry J, Hamilton K. Exercise induced cardioprotection: an overview and critical comparison with ischemic preconditioning. Curr Cardiol Rev. 2007;3(4):193-201.

7. Fallahi A, Gaeini A, Shekarfroush S, et al. Cardio-protective effect of high intensive interval training and nitric oxide metabolites. Iran J Public Health. 2015;44(9):1270-1276.

8. Kavazis AN. Exercise preconditioning of the myocardium. Sports Med. 2009;39(11):923-935.

9. Frasier CR, Moore RL, Brown DA. Exercise-induced cardiac preconditioning: how exercise protects your achy-breaky heart. J Appl Physiol. 2011;111(3):905-915.

10. Lennon S, Quindry J, French J, et al. Exercise and myocardial tolerance to ischaemia-reperfusion. Acta Physiol Scand. 2004a;182(2):161-169.

11. Gibala MJ, Little JP, MacDonald MJ, et al. Physiological adaptations to low-volume, high-intensity interval training in health and disease. $J$ Physiol. 2012;590(5):1077-1084.

12. Gibala MJ, Little JP, Van Essen M, et al. Short-term sprint interval versus traditional endurance training: similar initial adaptations in human skeletal muscle and exercise performance. $J$ Physiol. 2006;575(Pt 3):901-911.
13. Haram PM, Kemi OJ, Lee SJ, et al. Aerobic interval training vs. continuous moderate exercise in the metabolic syndrome of rats artificially selected for low aerobic capacity. Cardiovasc Res. 2009;81(4):723-732.

14. Freyssin C, Verkindt C, Prieur F, et al. Cardiac rehabilitation in chronic heart failure: effect of an 8 -week, high-intensity interval training versus continuous training. Arch Phys Med Rehabil. 2012;93(8):1359-1364.

15. Guiraud T, Nigam A, Gremeaux V, et al. High-intensity interval training in cardiac rehabilitation. Sports Med. 2012;42(7):587-605.

16. Wisløff U, Ellingsen $\varnothing$, Kemi OJ. High-intensity interval training to maximize cardiac benefits of exercise training? Exerc Sport Sci Rev. 2009;37(3):139-146.

17. Gibala MJ, Jones AM. Physiological and performance adaptations to high-intensity interval training. Nestle Nutr Inst Workshop Ser. 2013;76:51-60.

18. Libonati JR, Kendrick ZV, Houser SR. Sprint training improves postischemic, left ventricular diastolic performance. J Appl Physiol. 2005;99(6):2121-2127.

19. Rognmo Ø, Moholdt T, Bakken H, et al. Cardiovascular risk of high-versus moderate-intensity aerobic exercise in coronary heart disease patients. Circulation. 2012;126(12):1436-1440.

20. Tabata I, Nishimura K, Kouzaki M, et al. Effects of moderate-intensity endurance and high-intensity intermittent training on anaerobic capacity and VO2max. Med Sci Sports Exerc. 1996;28(10):1327-1330.

21. Swain DP, Franklin BA. Comparison of cardioprotective benefits of vigorous versus moderate intensity aerobic exercise. Am J Cardiol. 2006;97(1):141-147.

22. Rankin AJ, Rankin AC, MacIntyre P, et al. Walk or run? Is high-intensity exercise more effective than moderate-intensity exercise at reducing cardiovascular risk? Scott Med J. 2012;57(2):99-102.

23. Lennon SL, Quindry J, Hamilton KL, et al. Loss of exercise-induced cardioprotection after cessation of exercise. J Appl Physiol. 2004b;96(4):1299-1305.

24. Rahimi M, Shekarfroush S, Asgari A, et al. The effect of high intensive internal training on cardioprotection against ischemic reperfusion injury in Wister rat. EXCLI J. 2015;14:237-246.

25. Quindry J, French J, Hamilton K, et al. Exercise training provides cardioprotection against ischemia-reperfusion induced apoptosis in young and old animals. Exp Gerontol. 2005;40(5):416-425.

26. Tjønna AE, Lee SJ, Rognmo Ø, et al. Aerobic interval training versus continuous moderate exercise as a treatment for the metabolic syndrome: a pilot study. Circulation. 2008;118(4):346-354. 